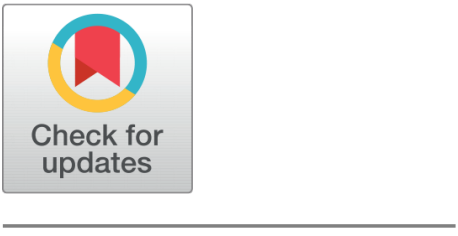

open ACCESS

Received: 18.01.2021

Accepted: 21.04 .2021

Published: 18.05.2021

Citation: Taddese ET, Gessel D, Han X (2021) Chinese Language Learning Anxiety: The Case of International Students in Northeast Normal University. Indian Journal of Science and Technology 14(18): 1434-1441. https://doi.org/ 10.17485/JJST/v14i18.26

* Corresponding author.

taid342@nenu.edu.cn

Funding: None

Competing Interests: None

Copyright: (ㄷ 2021 Taddese et al. This is an open access article distributed under the terms of the Creative Commons Attribution License, which permits unrestricted use, distribution, and reproduction in any medium, provided the original author and source are credited.

Published By Indian Society for Education and Environment (iSee)

ISSN

Print: 0974-6846

Electronic: 0974-5645

\section{Chinese Language Learning Anxiety: The Case of International Students in Northeast Normal University}

\author{
Esayas Teshome Taddese ${ }^{1 *}$, Déborah Gessel ${ }^{1}$, Xue Han ${ }^{1}$ \\ 1 Northeast Normal University, 5268 Renmin Street, Changchun City, Jilin, China
}

\section{Abstract}

Objectives: This research was carried out to investigate Chinese language learning anxiety of international students in Northeast Normal University, China. Specifically, the study looked into the differences in Chinese language learning anxiety between African and Asian international students according to their continent, gender and study program (MA and PhD). Methods: The study employed quantitative research design to attain its objectives; the instrument adapted is the Foreign Language Classroom Anxiety Scale (FLCAS) developed by ${ }^{(1)}$. This instrument has 31 items in total. The participants of the study were 80 postgraduate international students from Africa and Asia. Descriptive statistics, independent sample t-test and Pearson Correlation test were used to analyze the data. Findings: The results obtained indicate that there is no statistically significant difference in the Chinese language learning anxiety based on the continent and gender of the participants, but significant differences were found between the levels of anxiety among students owing to their level of study. Correlation test revealed no significant relationship between Chinese language learning anxiety and the number of Chinese friends one has. Similarly, there is no relationship between Chinese language learning anxiety and the number of semesters of learning Chinese and the length of time lived in China. Note ${ }^{1}$

Keywords: International students; Chinese language; Anxiety; African students; Asian students

\section{Introduction}

\subsection{Background}

Learning a foreign language has become a common experience for many people now a days. The main reason is globalization and ease of mobility that urged the need to learn foreign languages in different contexts. However, learners of foreign languages or a foreign language experience different levels of anxiety in their attempt to learn foreign

\footnotetext{
${ }^{1}$ Note: Asia-in the context of this study refers to all countries in the continent except China.
} 
languages. The factors that cause such variability in learners' anxiety include learner's background, gender, age and individual differences among others ${ }^{(2)}$. As a result the issue of foreign language learning has attracted the attention of researchers from around the world; and ${ }^{(1)}$ were the first scholars to take up the issue of anxiety in foreign language learning ${ }^{(3)}$. Since then tremendous researchers have studied foreign language learning anxiety experienced by learners of various foreign languages. Of course, the majority of the previous studies focused on English as Foreign Language (EFL) learners because of the popularity of the English language throughout the world.

However, the focus of the present study is on Chinese language learning anxiety experienced by international students in China. In this regard, figures from the last ten years show that international students coming to China are significantly increasing. These students take Chinese language courses or a course, however, the anxiety level that these students experience while studying Chinese language was not exhaustively investigated so far. One study that can be mentioned in this regard is the study conducted by ${ }^{(4)}$ that investigated Chinese language learners' anxiety in the context of U.S.A. Thus the study didn't address Chinese language learners' experiences in the context of China where the learners have better exposure to the target language. Therefore, this study focuses on examining the Chinese language learning anxiety experienced by international students in Northeast Normal University (NENU) located in Changchun City, Jilin Province, China. The Chinese language course these students take includes one compulsory course and optional courses. In undertaking the Chinese language course(s) different students experience different anxiety levels. Some are considered very anxious while others may be less anxious. In cases where the anxiety level is high, research confirmed that it affects the learner's performance unless it is handled wisely ${ }^{(5)}$.

\subsection{Purpose of the study}

Foreign language learning anxiety is undesirable communication apprehension and unpleasant emotional condition that affects the language learning performance of students. Studies confirmed that students with high levels of anxiety receive lower scores than students with lower anxiety levels ${ }^{(5-7)}$. Therefore, an effort to reduce and settle down the anxiety level of foreign language learners is very important for facilitating the target language learning.

Accordingly, there are tremendous studies conducted on foreign language learning anxiety in different countries across the globe, but in order to get a better understanding of language learning anxiety, it appears important to further explore why different learners become anxious when learning different foreign languages. In the past most of the foreign language anxiety studies were conducted on English as a foreign language because of its popularity throughout the world ${ }^{(8)}$. However, in recent time Chinese language is becoming a competent language in attracting the attention of learners from across the world. The economic and political empowerment of China and its global influence promoted Chinese language. In this case it is evident to mention the Chinese language programs underway in many countries in Africa, Asia, Latin America, North America and Europe. Accordingly there are many people studying Chinese language in their home country and in China through different scholarship and non-scholarship programs as of now. Therefore, exploring the Chinese language learning anxiety that learners of different backgrounds experience sounds sensible issue. Thus, the purpose of this study was to explore the anxiety level of African and Asian (non-Chinese) international students in Northeast Normal University in China while studying Chinese language.

\subsection{The Hypothesis}

The study started with the following two hypotheses:

\section{Hypothesie-1:}

There is significant difference in Chinese language learning anxiety scores between international students according to their continent, gender and study program.

\section{Hypothesie-2:}

The background variables (number of Chinese friends one has, the number of months one has lived in China, number of semester Chinese language course(s) attended in China and number of months spent on studying Chinese language in home country) has significant relationship with Chinese language learning anxiety score of international students. 


\section{Literature Review}

\subsection{What is anxiety?}

Anxiety, as applied to foreign language learning, has been defined by several researchers who have tried to study the issue. ${ }^{\left({ }^{(9)}\right.}$, for example, defined foreign language anxiety as feelings of discomfort, unstable self-esteem, and self-confidence construct that affects learners' psychological phenomenon. ${ }^{(10)}$ defined it as feeling of tension and negative emotional reaction that foreign language learners experience. In addition to this, ${ }^{(11)}$ defined foreign language learning as the psychological tension that inhibits learners from pursuing their study. All of these definitions, of course, are built around the claim made by ${ }^{(1)}$ who studied foreign language learning anxiety for the first time. According to ${ }^{(1)}$, foreign language learning anxiety is fear that happens by the time learners try to perform in the foreign language. Furthermore, they explained three interrelated components underlying learners' foreign and second language learning anxiety: communication apprehension, fear of negative evaluation and test anxiety. This idea has greatly influenced the flourishing studies that have been done on the subject matter in varied context since the mid1980s.

\subsection{Facilitative and Debilitative Anxiety}

Anxiety experienced in Foreign or second language learning context can take two forms: facilitating and debilitating anxiety. This in turn can influence students' learning either positively or negatively. Facilitative anxiety is helpful in alerting the learner for hard work while debilitative anxiety is associated with negative feelings like frustration, nervousness, uneasiness, apprehension and tension, and limits the learner from learning the language effectively ${ }^{(1,12,13)}$.

\subsection{Causes of Foreign Language Learning Anxiety}

To maintain effective foreign/second language learning, understanding the possible cause of the underlying anxiety is important. A review of the literature on foreign language anxiety indicates that the causes of foreign language learning anxiety include learners' self-perceived incompetence and classroom-related variables (teacher, peer, classroom practice) ${ }^{(14,15)}$. Besides, ${ }^{(16)}$ identified six sources for classroom anxiety. These are: personal and interpersonal anxieties, learner beliefs about language learning, instructor beliefs about language teaching, instructor-learner interactions, classroom procedures, and language testing ${ }^{(17)}$. So it is helpful to take into consideration anxiety provoking classroom procedures.

\section{Methods}

\subsection{Research Design}

This study employed quantitative research design to examine the Chinese language learning anxiety of international students coming from African and Asian countries. Doing this helped the study to objectively measure the Chinese language learning anxiety of the learners' and to reach an objective conclusion.

\subsection{Target Population and Sampling Technique}

The target population of the study included all active $\mathrm{MA}$ and $\mathrm{PhD}$ international students at Northeast Normal University in the spring semester of the 2019 academic year. Taking one semester Chinese language course is mandatory for both MA and PhD program students. Therefore, these students have taken at least one Chinese language course, and they experienced anxiety of studying Chinese as a foreign language. A simple random sample technique was used to select the participants of the study.

\subsection{Data Collection Tools}

This study used both open ended and close ended questionnaire items. The total questionnaire items were 31 . The first nine items were about the background information of the participants, and the rest 22 Likert scale items were the Foreign Language Anxiety Scale (FLAS) adapted from the works of ${ }^{(1)}$. The FLAS has been used by many more related studies and was very recently proved repeatedly for its reliability and validity as a measure of foreign language learning anxiety ${ }^{(18)}$. However, minor modifications were made on the scale to fit it to the context of learning Chinese as a foreign language. 


\subsection{Method of Data Analysis}

As the research design was quantitative, the analysis of the data was done quantitatively using Statistical Package for Social Science (SPSS) version 21. Then it was summarized using descriptive statistics namely mean, frequency distribution and percentage. The study also employed independent sample $t$-test to see if African and Asian international students experience significantly different Chinese language learning anxiety. The independent sample t-test used also helped the study to see if gender difference affected the Chinese language learning anxiety level. The study also used correlation test to see the relationship between the participants' background traits and Chinese language learning anxiety.

\section{Results}

This section presents the data analysis and interpretation. The study used independent sample t-test to determine the significance of the difference in Chinese language learning anxiety of international students. The study considered continent, gender and study program (MA and $\mathrm{PhD}$ ) as variables to see differences in Chinese language learning anxiety. Furthermore, the study used correlation test to determine the association between Chinese language learning anxiety and number of Chinese friends one has, the number of months one has lived in China, number of semester Chinese language course attended in China and number of months spent on studying Chinese language in home country as variables (See table 1 for details).

Table 1. Participant's Background Information

\begin{tabular}{lll}
\hline Participants variables & Frequency & Percent \\
\hline African & 40 & 50 \\
Asian & 40 & 50 \\
Male & 51 & 63.75 \\
Female & 29 & 36.25 \\
MA students & 56 & 70 \\
PhD students & 24 & 30 \\
Total & 80 & 100 \\
\hline
\end{tabular}

\subsection{Interpretation of the anxiety scores}

To measure the level of Chinese language learning anxiety, a questionnaire having 31 items was used. The first 9 items were background information questions and the rest 22 were foreign language anxiety scale (FLAS) items. Since these 22 questionnaire items are 5 scale items, the total anxiety score ranged from 22 to 110 . The difference between these values is 88. Accordingly, the participants with anxiety score of 74 and above are considered as having high anxiety. Those who score in the range of 52-73 are taken as experiencing moderate anxiety while the others with anxiety scores below 51 are categorized as having low anxiety experiences (Table 2 has more).

Table 2. Chinese language learning Anxiety score

\begin{tabular}{lll}
\hline Response & Frequency & Percent \\
\hline Participants with high anxiety level $>=74$ & 3 & 3.75 \\
Participants with moderate anxiety level $[52-73]$ & 60 & 75 \\
Participants with low anxiety score level $<51$ & 17 & 21.25 \\
\hline Total & 80 & 100 \\
\hline
\end{tabular}

The majority (75\%) of the respondents exhibited moderate Chinese language learning anxiety. The overall mean for the anxiety score $(\mathrm{M}=59.83 ; \mathrm{SD}=11.94, \mathrm{~N}=80)$ of the participants also falls within the moderate anxiety level range. This moderate anxiety level of students indicates that there is little anxiety provoking practices in Chinese language classes.

\subsection{Chinese language learning Anxiety (Asian vs African students)}

An independent sample t-test was ran to determine if there were differences in Chinese language learning anxiety between international students coming from Asia and Africa. The mean of the anxiety score for each group were normally distributed and equal variance was assumed. A total of 40 international students from Africa and 40 international students from Asia were considered for the independent sample t- test. The African $(\mathrm{N}=40, \mathrm{M}=2.82, \mathrm{SD}=.555)$ and the Asian $(\mathrm{N}=40, \mathrm{M}=2.67, \mathrm{SD}=.520)$ groups were compared for the Chinese language learning anxiety score. The independent sample $t$-test, $t(78)=1.179, p<.05)$, indicated that there is no statistically significant difference in Chinese language learning anxiety score between the Asian and 
African international students at $95 \%$ confidence interval. As a result the study failed to reject the null hypothesis that claims there is no significant Chinese language learning anxiety between African and Asian international students.

\subsection{Chinese language learning Anxiety (Male vs Female students)}

Independent samples t-test was ran to compare the Chinese language learning anxiety score of men and women international students. The anxiety score of the women $(\mathrm{N}=29, \mathrm{M}=2.662, \mathrm{SD}=.5393)$ and men $(\mathrm{N}=51, \mathrm{M}=2.792, \mathrm{SD}=.5085)$ revealed a slightly different mean score. However, the independent sample t-test result, $\mathrm{t}(78)=1.040, \mathrm{p}<.05$, proved that the Chinese language learning anxiety score between men and women is statistically not significant at $95 \%$ confidence interval of the difference. Hence, the study failed to reject the null hypothesis; and it can be argued that gender difference does not cause difference in anxiety score of Chinese language learning. Both men and women can learn Chinese language without experiencing significantly different anxiety because of the gender difference.

\subsection{Chinese language learning Anxiety (MA vs PhD students)}

The study compared MA international students $(\mathrm{N}=56, \mathrm{M}=2.84, \mathrm{SD}=.5416)$ and $\mathrm{PhD}$ international students $(\mathrm{N}=24, \mathrm{M}=2.53$, $\mathrm{SD}=.4841$ ) for differences in Chinese language learning anxiety score. Assuming equal variance, the independent $\mathrm{t}-\mathrm{test}$ at $\mathrm{t}$ $(77)=2.35, \mathrm{p}<.05$ for the mean difference in anxiety score revealed that there is statistically significant difference in Chinese language learning anxiety between MA and PhD international students. That means the MA international students are more anxious in learning Chinese language than $\mathrm{PhD}$ international students are. Hence, the study rejected the null hypothesis that claims there is no significant difference in Chinese language learning anxiety between MA and PhD program students. The PhD program students' age (32 years) on average makes them older than the MA students (29.5 years) in this study. Therefore, it can be argued that having longer life experience helps with coping anxious situations. In addition, compared with the MA program the $\mathrm{PhD}$ program takes longer to complete successfully. Hence, $\mathrm{PhD}$ students have a better chance at repeating the course if failed. This might be the reason why the $\mathrm{PhD}$ students are less anxious. Detail of the independent t-test is given in Table 3.

Table 3. Independent Samples Test

\begin{tabular}{|c|c|c|c|c|c|c|c|c|c|c|}
\hline & & \multicolumn{2}{|c|}{$\begin{array}{l}\text { Levene's Test for } \\
\text { Equality of Vari } \\
\text { ances }\end{array}$} & \multicolumn{7}{|c|}{ t-test for Equality of Means } \\
\hline & & \multirow[t]{2}{*}{$\mathrm{F}$} & \multirow[t]{2}{*}{ Sig. } & \multirow[t]{2}{*}{$\mathrm{t}$} & \multirow[t]{2}{*}{ df } & \multirow[t]{2}{*}{$\begin{array}{l}\text { Sig. (2- } \\
\text { tailed) }\end{array}$} & \multirow[t]{2}{*}{$\begin{array}{l}\text { Mean } \\
\text { Difference }\end{array}$} & \multirow[t]{2}{*}{$\begin{array}{l}\text { Std. Error } \\
\text { Difference }\end{array}$} & $\begin{array}{l}95 \% \\
\text { Interval } \\
\text { Difference }\end{array}$ & $\begin{array}{l}\text { Confidence } \\
\text { of the } \\
e^{\text {of }}\end{array}$ \\
\hline & & & & & & & & & Lower & Upper \\
\hline \multirow[t]{2}{*}{$\begin{array}{l}\text { Anxiety } \\
\text { mean }\end{array}$} & $\begin{array}{ll}\text { Equal } & \text { variances } \\
\text { assumed } & \end{array}$ & .559 & .457 & 2.350 & 77 & .021 & .30603 & .13023 & .04672 & .56535 \\
\hline & $\begin{array}{l}\text { Equal variances not } \\
\text { assumed }\end{array}$ & & & 2.464 & 45.617 & .018 & .30603 & .12420 & .05597 & .55610 \\
\hline
\end{tabular}

\subsection{Correlation}

This study used correlation to see the relationship between international students' background traits (number of Chinese friends one has, the number of months one has lived in China, number of semester Chinese language course attended in China and number of months spent on studying Chinese language in home country). See Table 4 below for the descriptive statistics of these participants' background traits. The participants have 11 Chinese friends on average, and they lived in China for 19.85 months on average. They also took Chinese language course on average for 2 semesters in China.

Table 4. Descriptive Statistics

\begin{tabular}{lll}
\hline Group traits & N & Mean \\
\hline Number of Chinese friends one has & 78 & 11.4103 \\
Number of Months one has lived in China & 80 & 19.8500 \\
$\begin{array}{l}\text { Number of semester Chinese language course attended } \\
\text { in China }\end{array}$ & 80 & 2.3250 \\
$\begin{array}{l}\text { Number of months spent on studying Chinese language } \\
\text { in home country }\end{array}$ & 80 & 1.4750 \\
\hline
\end{tabular}


The correlation test started with correlating the participants' Chinese language learning anxiety score with the number of Chinese friends the participants have; however, the test revealed a weak negative Pearson correlation $(\mathrm{r}=-.198, \mathrm{~N}=80, \mathrm{p}=$ 0.83 ) This implies that there is no statistically significant correlation. Similarly, the study investigated the correlation between international students' Chinese language learning anxiety score and the length of time one has lived in China. The correlation test shows very weak negative correlation $(\mathrm{r}=-.142, \mathrm{~N}=80, \mathrm{p}=0.209)$. So, it can be concluded that there is no significant correlation between the variables. The result of the Pearson bivariate correlation analysis also shows that participants' Chinese language learning anxiety score and the time spent on studying Chinese language in China and back in their home country had no statistically significant correlation. Therefore, the study failed to reject the null hypothesis that states there is no significant relationship between the participants' background variables (number of Chinese friends one has, the number of months one has lived in China, number of semester Chinese language course attended in China and number of months spent on studying Chinese language in home country) and their Chinese language learning anxiety scores.

\section{Discussion}

It was found that African and Asian international students at Northeast Normal University do not have statistically significant different anxiety experience in their Chinese language classes. The independent sample t-test proved that the difference in the mean anxiety score of the two groups is statistically insignificant. Hence, it can be concluded that African and Asian international students experience Chinese language classes in the same manner regardless of the geographical and cultural proximity they have with China. Yet, ${ }^{(19)}$ reported that having knowledge of the target culture helps in studying the target language because of the intertwined nature of culture and language. Similarly, the independent sample t-test ran between men and women international students revealed that there is no statistically significant difference between the mean anxiety score of the two groups in their Chinese language classes. Hence, men and women can study Chinese language courses in undifferentiated classes without differences. This conclusion of the study coincides with the finding reported by ${ }^{(20-24)}$ who found that foreign language anxiety did not differ with gender. However, the result is conflicting with ${ }^{(25-29)}$ who reported that there is statistically significant variation in foreign language learning anxiety between men and women. These conflicting conclusions may account the differences in the study context and participants. This study is particularly about international students experience on learning Chinese language while the previous studies were done on English as a foreign language anxiety.

However, in the comparison between $\mathrm{MA}$ and $\mathrm{PhD}$ students' Chinese language learning anxiety score, the independent sample t-test proved that there is statistically significant difference between the groups. The MA students were found more anxious as compared to $\mathrm{PhD}$ program students. The $\mathrm{PhD}$ students in this study are on average older than the MA students, and the result indicate that the $\mathrm{PhD}$ (the older) students are less anxious in their Chinese language study. However, previous studies by ${ }^{(21)}$ ascertained that older students possess higher levels of anxiety than younger students do. On the other hand, ${ }^{(30)}$ reported that being adult learners would enhance positive motivation and self-efficacy towards learning foreign language. Contextual differences may account to this kind of conflicting results. Thus doing more comprehensive study could help to clear such discrepancies in results.

On the other hand, the correlation test shows that there is no significant association between the participants' traits (number of Chinese friends one has, the number of months one has lived in China, number of semester Chinese language course attended in China and number of months spent on studying Chinese language in home country) and Chinese language learning anxiety score. This implies that the length of time one lives in China, without the individuals effort to learn the target language, does not guarantee learning the language. However, this finding contrast with ${ }^{(24)}$ who concluded that the longer a student spends learning a foreign language the less language anxiety he/she will experience.

Although it is true that having the target language exposure is helpful in foreign language learning, this study proved that the number of friends one might have from the target language speakers (number of Chinese friends in this case) has no association with one's Chinese language learning anxiety. The individuals' effort to use the opportunity for improving his/her Chinese language matters.

\section{Conclusion}

This research was carried out to investigate Chinese language learning anxiety of international students. The results revealed that most of the international students had moderate anxiety experience in learning Chinese as a foreign language. No significant difference among African and Asian international students in their Chinese language learning anxiety experiences was reported. Similarly female and male students have no significantly different anxiety. Similarly, no significant differences were found between the levels of anxiety among participants due their gender differences. However, significant differences were found between the levels of anxiety among students owing to their level of study ( $\mathrm{PhD}$ and $\mathrm{MA}$ ). But this finding cannot be enough 
evidence to conclude that two groups need different treatment in Chinese language classes. On the other hand, the correlation test ran to determine the relationship between participants' background traits (number of Chinese friends one has, the number of months one has lived in China, number of semester Chinese language course attended in China and number of months spent on studying Chinese language in home country) and Chinese language learning anxiety shows no significant correlation. That means none of the correlation tests revealed significant correlation. It is thus, concluded that the number of Chinese friends one has and the length of time spent on taking Chinese language course both in home country and China have neither positive nor negative association with the learners' anxiety experience.

The conflicting results of studies on the Chinese as foreign language learning anxiety as indicated in the discussion section, however, suggested the need for further large scale studies on international students studying in China to examine the variables that account to the students' Chinese as foreign language learning anxiety.

\section{Limitations of the study}

The participants of this study came from very diverse backgrounds. The cultural and linguistic diversity of each of the participants were likely to impact on how confident the finding drawn was in relation to the descriptors as African and Asian international students. Moreover, the participants were relatively small and limited to only one University. Thus, larger studies with more participants from several Universities might bring better results. Including variables like age, academic major and specific countries of origin could help to come up with more comprehensive results. Besides, it would have been better to include qualitative data that can corroborate, update or illustrate the quantitative data such as individual or group interviews to understand the reasons underlying Chinese as a foreign language learning anxiety of students and what makes them motivated.

\section{References}

1) Horwitz EK, Horwitz MB, Cope JA. Foreign language classroom anxiety. . The Modern language Journal. 1986;70(2):125-132. Available from: https://www.jstor.org/stable/327317.

2) Suleimenova Z. Speaking anxiety in a foreign language classroom in Kazakhstan. Procedia- Social and Behavioral Sciences. 2013;93:1860-1868.

3) Cagatay S. Examining EFL students' foreign language speaking anxiety: The case at a Turkish state university. Procedia- Social and Behavioral Sciences. 2015;199:648-656.

4) Luo H. Foreign Language Speaking Anxiety: A Study of Chinese Language Learners. Journal of the National Council of Less Commonly Taught Languages. 2014;15:99-117.

5) Liu M. A study of Chinese University learners' anxiety in German language classrooms in at-home and study-abroad contexts. Cogent Education. 2018;5(1):1-14.

6) Samimy KK, Tabuse M. Affective variables and a less commonly taught language: A study in beginning Japanese classes. Language Learning. 1992;42:377398.

7) Karatas H, Alci B, Bademcioglu M, Ergin A. An Investigation into University Students' Foreign Language Speaking Anxiety. Procedia - Social and Behavioral Sciences. 2016;232:382-388.

8) Hashemi M. Language Stress and Anxiety among the English Language Learners. Procedia - Social and Behavioral Sciences. 2011;30:1811-1816.

9) Clement R. Ethnicity, contact, and communicative competence in a second language. In: Giles H, Robinson WP, Smith PM, et al., editors. Language: Social psychology and language. Pergamon Press. 1980;p. 147-159.

10) Macintyre PD, Gardner RC. The subtle effects of language anxiety on cognitive processing in the second language. Language Learning. 1994;44(2):283-305.

11) Zhang LJ. Exploring variability in language anxiety: Two groups of PRC students learning ESL in Singapore. RELC Journal. 2001;32(1):73-94.

12) Hu L, Wang N. Anxiety in Foreign Language Learning. In: and others, editor. International Conference on Global Economy, Commerce and Service Science. Atlantis Press. 2014.

13) Williams KE. Is "Facilitating Anxiety" All in Your Head? Sophia Junior College Faculty Journal. 2008;28:1-7.

14) Zhang R, Zhong J. The Hindrance of Doubt: Causes of Language Anxiety. International Journal of English Linguistics. 2012;2(3):27-33.

15) Liu M, Zheng Y, Ma, Wei Y. 2020.

16) Young DJ. Creating a low-anxiety classroom environment: What does language anxiety research suggest? . The Modern Language Journal. 1991;75(4):426437.

17) Sung, Ko-Yin, Li X. Factors Influencing Chinese Language Learning Anxiety in the Classroom Setting. New Waves Educational Research and Development. 2019;22(2):1-15.

18) Trang TT. A Review of Horwitz, Horwitz and Cope's Theory of Foreign Language Anxiety and the Challenges to the Theory. English Language Teaching. 2012;5(1):69-75.

19) Taddese ET. A Study on Students' Motivation to Learn Chinese Culture Course: The Case of 2018 Northeast Normal University International Students. Education Quarterly Reviews. 2019;2(1):116-121.

20) Aida Y. Examination of Horwitz, Horwitz, and Cope's Construct of Foreign language anxiety: The Case of Students of Japanese. Modern Language Journal. 1994;78(2):155-167.

21) Onwuegbuzie AJ, Bailey P, Daley CE. Factors Associated with Foreign Language Anxiety. Applied Psycholinguistics. 1999;20:217-239.

22) Basith A, Musyafak N, Ichwanto MA, Syahputra A. Chinese Learning Anxiety on Foreign Students. European Journal of Educational Research. 2019;8(4):1193-1200.

23) Luo H. Chinese language learning anxiety and its associated factors. Journal of Chinese Language Teachers Association. 2013;48(2):109-133.

24) Latif N. A Study on English Language Anxiety among Adult Learners in Universiti Teknologi Malaysia. Procedia - Social and Behavioral Sciences. 2015;208:223-232. 
25) Cheng Y. Factors associated with foreign language writing anxiety. Foreign Language Annals. 2002;35:647-656.

26) Elkhafaifi H. Listening Comprehension and Anxiety in the Arabic Language Classroom. Modern Language Journal. 2005;89(2):206-221.

27) Gerencheal B, Mishra D. Foreign Language Anxiety among Ethiopian University EFL Students. International Journal of Innovative Technology and Exploring Engineering. 2019;8(7C):43-48.

28) Sultan S. Students' perceived competence affecting level of anxiety in learning English as a foreign language. Pakistan Journal of Psychological Research. 2012;27(2):225-239.

29) Rezazadeh M, Tavakdi M. Investigating the Relationship among Test Anxiety, Gender, Academic Achievement and Years of Study: A Case of Iranian EFL University Students. English Language Teaching. 2009;2(4):68-74.

30) Majid FA, Othman SH, Rahmat K. Adult Learners' Characteristics and Their Anxiety in Online Language Learning. Innovation and Intervention in ELT: Pathways and Practices. 2007;5(2):201-223. 